Recebido: $20 / 02 / 2016$

Aprovado: $21 / 08 / 2017$

\title{
A Nova História no Brasil: Um estudo das apropriações teóricas e metodológicas no livro Festas e Utopias no Brasil Colonial de Mary Del \\ Priore.
}

Thiago Granja Belieiro*

Resumo: O presente artigo tem por objetivo analisar as relações teóricas e metodológicas entre a historiografia brasileira e a terceira e a quarta geração dos Annales. Tendo como fonte de investigação o livro Festas e Utopias no Brasil Colonial da historiadora brasileira Mary Del Priore, procura-se através desta visualizar uma pequena parte das apropriações de conceitos, temas e metodologias de pesquisa da historiografia francesa que aportam em parte importante da produção historiográfica brasileira nos final dos anos 80 e início dos anos 90. Cercando-se da perspectiva teórica de Michel de Certeau, Pierre Bourdieu e Roger Chatier, a investigação vai caminhar no sentido de perceber como se deram a apropriação de conceitos, teorias e métodos da historiografia francesa na obra escolhida como fonte, notando ainda como tais apropriações são fundamentais para a Operação Historiográfica.

Palavras Chave: Historiografia; teoria; apropriação.

Abstract: This article aims to analyze the theoretical and methodological links between Brazilian historiography and the third and fourth generation of the Annales. Having as research source the book Festivals and Utopias in Brazil Colonial Brazilian historian Mary Del Priore, looking up through this view a small portion of the appropriation of concepts, issues and research methodologies of French historiography that contribute in an important part of the historical production Brazil in the late $80 \mathrm{~s}$ and early 90 s Surrounding from the theoretical perspective of Michel de Certeau, Pierre Bourdieu and Roger Chatier, the research will move towards realizing how was the appropriation of concepts, theories and methods of historiography French in the work chosen as the source, even noting how these appropriations are fundamental for the historiography operation.

Keywords: Historiography; theory; appropriation.

\footnotetext{
* Doutorando em História pela UNESP, Mestre em História pela UNES: E-mail: thiagobeli@hotmail.com
} 


\section{Introdução}

Não é possível pensar a produção historiográfica brasileira, principalmente no século $\mathrm{XX}$, sem considerar as relações teóricas e metodológicas com outros centros de produção de conhecimento histórico. Sendo assim, a produção historiográfica brasileira deste século é bastante influenciada pelo método Rankeano, mais tarde pelo Historicismo alemão e ainda, e notadamente, pelos estudos marxistas. Contudo, é com a Historiografia Francesa que os historiadores brasileiros guardam a mais íntima relação. (ROJAS, 2007: 13-31)

Nesse sentido, temas de estudo, teorias explicativas e métodos de pesquisa histórica oriundas da produção francesa se fazem presentes na produção historiográfica brasileira de maneira bastante significativa. Podemos notar a presença do pensamento francês em nossa historiografia desde a publicação do manual metodológico de Langlois e Seignobos, grande sucesso entre os historiadores brasileiros. Mas é o grupo reunido em torno da Revista dos Annales que vai ter presença marcante no campo historiográfico brasileiro; notadamente com a terceira e a quarta geração do grupo.

Nesse artigo, vamos considerar a relação da historiografia brasileira com a terceira e a quarta geração do grupo dos Annales. Com nomes como Jacques Le Goff na terceira e Roger Chartier na quarta geração, tal grupo vai dar início a uma revolução historiográfica a partir da publicação, em 1974, da obra manifesto História: novos problemas, novos objetos e novas abrodagens, em que apresentam as bases daquilo que seria conhecido como a Nova História, com parte significativa desses pressupostos sendo seguidos pela quarta geração, essa mais conhecida como Nova História Cultural. (BURKE, 1990, BURKE, 2005, HUNT, 1992)

Com efeito, a terceira geração e a quarta geração dos Annales procuraram não só dar continuidade ao legado recebido das gerações anteriores, como, efetivamente, buscou-se afirmar no campo historiográfico ao tentar criar novos paradigmas de explicação histórica, novas metodologias de pesquisa e, principalmente, novos temas de interesse para o historiador.

Nesse sentido, os novos paradigmas foram se estruturando em torno das relações epistemológicas que a historiografia francesa buscou estabelecer com as ciências sociais, notadamente, com a antropologia. Tal relacionamento pode ser explicado não só pelos interesses em conceitos e teorias explicativas, mas deveu-se também às disputas dentro do campo acadêmico francês, uma vez que a historiografia, tentando-se manter hegemônica

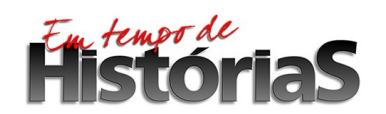


academicamente, aproximou-se das ciências sociais que, naquele momento, adquiriam certa notoriedade e espaço dentro da academia. (REIS, 2004, BELIEIRO, 2013)

Os ganhos epistêmicos para Clio são inúmeros a partir daí e muitos deles relacionam-se à ampliação do conceito de cultura e também pela noção de alteridade; pela incorporação dos estudos da cultura popular, pelo desenvolvimento da história do cotidiano e da vida privada, além de todo o desenvolvimento em torno da história das mentalidades e do imaginário. Além disso, temas como a festa, o corpo, o livro e aqueles relacionados à história religiosa são exemplos do que há de novo na Nova História e na Nova História Cultural.

O pequeno panorama esboçado acima serve apenas para que situemos a produção historiográfica francesa a partir dos anos 1970 mostrando alguns dos caminhos que ela tomou a partir dos trabalhos da terceira e da quarta geração do grupo dos Annales.

Nosso objetivo aqui é pensar como historiadores brasileiros da geração dos anos 80 e 90 foram influenciados por esse grupo e como, a partir de tal influência, ocorreu um rico processo de apropriação de temas, conceitos e métodos na produção historiográfica brasileira. Para tanto, vamos realizar a análise do livro Festas e Utopias no Brasil Colonial, da historiadora brasileira Mary Del Priore. A escolha desse texto como fonte justifica-se na medida em que se pode perceber nele a presença de várias influências teóricas e metodológicas oriundas da produção francesa, contudo, apontamos para o fato de que este é apenas um estudo dentre inúmeros escritos e publicados no período, com isso, ainda que representativo do processo de apropriação aqui perseguido, não se pode tomar o mesmo como referência completa do que então se fazia na historiografia brasileira, marcada então por um grande ecletismo teórico e metodológico. (RAMOS, 2014)

Partindo de uma abordagem de análise socioepistemológica tal como preconizada por Michel de Certeau (CERTEAU, 2002: 45-115), aliada ao pensamento de Pierre Bourdieu (BOURDIEU, 2002, BOURDIEU, 1977), sobre o campo acadêmico, temos a seguinte situação analítica que se divide em três conjuntos de reflexões.

A primeira dessas reflexões é aquela que considera o lugar para a operação historiográfica ocorrer, ou seja, a instituição onde tal texto de história é produzido. Nesse aspecto, é de grande importância então considerar qual a universidade, o programa de pósgraduação e suas linhas de pesquisa, e ainda, pensar em como estão constituídas as relações de autonomia e dependência entre esse lugar, visto como um campo autônomo e ao mesmo tempo dependente das determinações do contexto sócio cultural e político em que está situado.

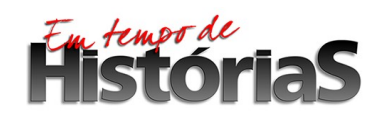


A partir desse primeiro aspecto, podemos então partir para o segundo escopo de reflexões, ou seja, considerar a prática dos agentes desse lugar e campo; e nesse sentido, analisar as metodologias de pesquisa empregadas, as teorias explicativas mobilizadas. Dentro disso, considerar e concentrar-se nos processos de apropriação ${ }^{1}$ de conceitos, teorias e métodos de pesquisa oriundos do campo historiográfico francês e que se fazem presentes no campo historiográfico brasileiro.

O terceiro aspecto dessas reflexões é aquele da escrita, ou seja, da consideração do texto ou discurso histórico como resultado das complexas relações entre o lugar e a prática. Sendo assim, o texto histórico é o resultado dessa interação epistemológica e é visto como revelador de um modelo científico, ou seja, de práticas disciplinares de pesquisa. É isso o que nos permite eleger o livro Festas e Utopias no Brasil Colonial como uma fonte histórica para análise historiográfica aqui proposta.

\section{O campo historiográfico brasileiro entre meados dos anos 80 a meados dos anos 90.}

Os anos 80 são considerados anos de grande mudança no modo de fazer historia no Brasil. As mudanças na organização da pós-graduação realizadas na década anterior deram grande impulso aos programas de pós em História de inúmeras universidades, seja pela consolidação dos mais tradicionais, seja pela ampliação de vagas e bolsas de estudos, seja pela criação de novos programas de pesquisa em universidades fora dos grandes centros. (FICO e POLITO, 1992: 31-61)

Significativa, nessa década, é também a renovação em termos de linhas de pesquisa, teorias, temas, ideias orientadoras, metodologias empregadas, naquilo que Astor Antônio Diehl chamou de mudança na Matriz Historiográfica Brasileira ${ }^{2}$. Para esse autor, os anos 80 são o grande momento de uma virada historiográfica na produção histórica brasileira, e essa

\footnotetext{
${ }^{1}$ Nesse trabalho vamos trabalhar a noção de apropriação tal como pensada por Roger Chartier em seus estudos sobre a história da leitura. Para esse autor, a apropriação deve ser pensada como um rico processo de interpretação onde entram em jogo as competências do leitor e principalmente o uso que se fará do texto lido em determinada situação, percebendo assim pluralidade dos modos de emprego e a diversidade das leituras, conforme as palavras do autor: "A apropriação, tais como as entendemos, tem por objetivo uma historia social das interpretações, remetidas para as suas determinações fundamentais (que são sociais, institucionais, culturais) e inscritas nas práticas especificas que as produzem". Assim, ao se debruçar sobre o texto histórico, poderemos perceber como se deu a apropriação e os usos e praticas de pesquisa que foram daí originada. CHARTIER, Roger. A história cultural: entre práticas e representações. 2. ed., Portugal: Difel, 2002, p. 26.

${ }^{2}$ A noção de Matriz Historiográfica é utilizada por Astor Antônio Diehl e refere-se às ideias, temas, modelos, teorias, métodos, representações, critérios de cientificidade e verdade, além dos modos de escrever a história em um determinado momento da produção historiográfica. DIEHL, Astor Antônio. A cultura historiográfica brasileira nos anos 1980. Porto Alegre, Evangraf, 1993.
}

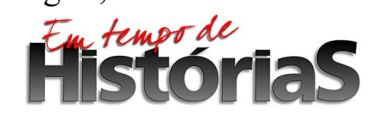


virada ocorre, segundo ele, a partir de uma crise das teorias otimistas de modernização e progresso, da crise do pensamento Marxista, à crise da recepção Max Weber, ao mesmo tempo em que ocorre uma sistemática recepção dos temas, métodos e abordagens da Nova História Francesa. (DIEHL, 1993: 07-13)

Ainda ligados a tais aspectos, Diehl aponta o fim da Ditadura Militar como uma explicação para tais mudanças, aliadas ao crescimento de uma indústria cultural editorial que passa a publicar as grandes obras da Nova História Francesa e que, de certa forma, vão dar incentivos à publicação de obras historiográficas com temáticas ligadas à Nova História, uma vez que essas são sucesso de público na França e no Brasil. (DIEHL, 1993: 07-13)

De fato, considerando a historiografia paulista, os anos 70 são marcados por uma produção historiográfica notadamente engajada, ou seja, durante os anos da Ditadura Militar, a historiografia paulista e "uspiana" postulam uma grande aderência às ideias marxistas como uma forma de luta contra o regime ditatorial então em vigor. (GLEZER, 2011). O fim do regime, em meados dos anos 80, vai permitir à historiografia certo desengajamento, ou melhor, um afastamento dos horizontes teóricos marxistas e uma aproximação mais tranquila com os novos problemas, os novos objetos e as novas abordagens, embora a presença do marxismo cultural seja de grande importância na produção historiográfica do período. Contudo, para Diehl, o fim da ditadura e a crise do pensamento Marxista abrem um vácuo na historiografia brasileira que será preenchido pela Nova História. (DIEHL, 1993, : 07-13)

Essa década assinala ainda a consolidação de um grande número de publicações de textos de história, com coleções temáticas e de divulgação, obras individuais, publicações de teses e dissertações, além, é claro, de traduções de textos de outros campos de produção de conhecimento histórico. (FICO e POLITO, 1992: 117-141)

Claro está que se estrutura nesses anos uma verdadeira indústria cultural consagrada a textos de história, chegando a atingir um número de 2037 títulos nacionais publicados e 621 títulos de trabalhos traduzidos.

Esse aspecto é relevante em nossa abordagem, pois, para que possam acontecer processos de apropriação cultural é necessário que os livros da produção francesa circulem no país, permitindo aos estudantes, pesquisadores e população em geral tomarem contato com o pensamento historiográfico de outras origens. Nesse sentido, segundo o levantamento realizado por Fico e Polito, as traduções do francês no período perfazem 30\% do total de livros traduzidos, perdendo apenas para os textos de língua inglesa que perfazem $45 \%$ do total. Com relação às traduções francesas, é notória a presença dos textos clássicos da Nova 
História, tais como os de Jacques Le Goff, Paul Veyne, entre outros. (FICO e POLITO, 1992: 122)

Com efeito, nota-se um imbricamento entre os interesses editoriais com os interesses de pesquisa, o que não é casual, uma vez que existe uma notável relação entre as editoras e as universidades. Assim, aos interesses de pesquisa por novos temas e novas abordagens, somam-se os interesses de uma indústria que espera lucro ao direcionar os esforços de publicação para tais temas que podem ter certo sucesso editorial em termos de vendas.

Naturalmente que a universidade, vista como lugar de produção de conhecimento histórico e como espaço onde se manifestam as determinações do campo acadêmico e historiográfico, é ambiente privilegiado no qual todas as mudanças apontadas ocorrem em primeiro plano. Dessa forma, relações com o contexto sócio histórico, abandono de certas teorias explicativas, debates em torno de novos temas e novas abordagens, circulação de ideias e livros, têm sempre a universidade como palco privilegiado de tais manifestações. As mudanças são sensivelmente notadas quando se consideram a configuração e as reconfigurações das linhas de pesquisa de determinado programa de pós-graduação.

Nesse sentido, é sensível a presença dos desdobramentos da Nova História em diferentes programas de pós-graduação do país, notadamente naqueles localizados no Estado de São Paulo. Em balanço de pesquisa divulgado na Revista Brasileira de História, publicado em 1994, por pesquisadores ligados à ANPUH, liderados pela historiadora Maria Helena Capelato, dentro do Projeto Pós-Graduação ANPUH: Pesquisa, Informação e Intercambio, nota-se a presença marcante de linhas de pesquisa ligadas à Nova História e da Nova História Cultural nos programas de Pós-Graduação da Unesp campus de Assis e campus de Franca, na Pontifícia Universidade Católica de São Paulo e também na Universidade de São Paulo.

Na UNESP de Assis, observa-se a presença nesse momento, 1994, da linha de pesquisa de História das Mentalidades, com disciplinas específicas da temática sendo oferecidas, e ainda, na UNESP de Franca nota-se a presença de linhas de pesquisa voltadas à História das Representações, e com a oferta de disciplinas de temas clássicos da Nova História, tais como história da família, e etno-história. Na Pontifícia Universidade Católica de São Paulo, aferimos a presença do eixo temático História e Cultura, com as linhas de pesquisa Cultura e Trabalho, Cultura e Cidades e Cultura e Representações. Na Universidade de São Paulo, especificamente, apontamos a presença da Linha de Pesquisa História e Cultura, com as sublinhas de arte e ciência, cultura material, imaginário, linguagens, memória e práticas culturais. (Revista Brasileira de História, 1994, 271-303).

\section{Filstistorias}


Dessa forma, o que se verifica é que, em meados da década de 90, as apropriações dos conceitos, temáticas e metodologias de pesquisa da Nova História e ainda da Nova História Cultural encontram-se institucionalizadas nos programas de pós-graduação das universidades paulistas. Juntamente com outras temáticas importantes, como história econômica e história política, e ainda com outras influências teóricas e metodológicas, a presença da influência dos historiadores franceses na produção historiográfica brasileira e paulista é fato.

Com efeito, são os programas de pós-graduação que vão dar aos pesquisadores as técnicas a serem empregadas, as fontes a serem estudadas e todas as escolhas dentro de um campo de possibilidades teóricas e metodológicas que serão fornecidas pelo lugar de produção de conhecimento histórico, conforme indica Michel de Certeau. Assim sendo, a escrita e o discurso histórico são resultado mais dessas determinações do que propriamente do gênio criador de determinado autor. Contudo, mesmo ligados a uma estrutura de produção de conhecimento que fornece os mecanismos, métodos, teorias e técnicas de pesquisa, que aponta fontes, modelos explicativos e do tipo de discurso a produzir, os agentes de produção de conhecimento histórico, ou melhor, os historiadores são foco importante de análise.

Para tal consideração, percebe-se uma interação entre o autor e o lugar, uma interação na qual determinado autor serve-se e coloca-se dentro de uma estrutura de produção, mas ao mesmo tempo, esse mesmo autor visto, como um agente, é capaz de causar alterações nessa estrutura de acordo sua formação, interesses e posição relativa dentro do campo acadêmico e historiográfico. Assim, o habitus ${ }^{3}$ de um determinado autor forma-se nessa estrutura, mas ao formar-se de maneira sempre complexa e variada pode também vir a modificar tal estrutura de produção de conhecimento.

A historiadora brasileira Mary Del Priore é autora de vasta obra dentro da historiografia brasileira e da história do Brasil. Privilegiando temas como história das mulheres, da infância e da família, a autora dedica-se ainda a temas como da história do amor, história e biografias, história da sexualidade, entre outros. Tendo publicado mais de vinte livros, a autora colaborou ainda com mais quatro dezenas de capítulos de livro, além de mais de uma centena de artigos.

\footnotetext{
${ }^{3}$ Para Bourdieu $O$ habitus é "um conhecimento adquirido, e também um haver, um capital (de um sujeito transcendental na tradição idealista) o habitus, a hexis, indica a disposição incorporada, quase postural ---, mas sim de um agente em ação (...)". Assim, o habitus é uma disposição incorporada, mas uma disposição é que também fruto da ação individual, de modo que assimilamos um habitus, mas também o construímos. No caso especifico dos historiadores, o habitus é adquirido na formação escolar e sobretudo acadêmica, assim, é nesse processo de formação que se dá na graduação, e depois nos programas de pós-graduação (aí se incluem seminários, congressos, iniciações científicas, participações em grupos de estudos, afinidades teóricas, entre outras) é que se incorpora as disposições do campo em agir e pensar cientificamente e historiograficamente. BOURDIEU, 1977, p. 117. BOURDIEU, 2002.
}

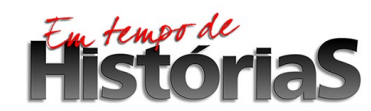


Mary Del Priore ${ }^{4}$ formou-se em história na Pontifícia Universidade Católica de São Paulo, no ano de 1983, em pleno processo de mudança da matriz historiográfica brasileira em direção aos novos temas, objetos e abordagens. Segundo Fico e Polito, a PUC de São Paulo sofria uma influência menor do contexto sociopolítico, ou seja, gozava-se naquela instituição de uma autonomia maior do campo acadêmico com relação ao campo político, o que, de certa forma, permitia a essa instituição um desengajamento maior com relação à historiografia marxista e uma abertura mais flexível a outras possibilidades teóricas e metodológicas.

A partir de 1986, a autora passa a integrar a pós-graduação na Universidade de São Paulo, onde realiza pesquisa dentro da área de história das mentalidades, enfocando a questão do corpo e da sexualidade feminina. O resultado dessa pesquisa é sua tese de doutoramento defendida no ano de 1990 com o título: Ao sul do corpo: condição feminina, maternidade e mentalidade no Brasil Colônia. Interessante notar como a autora produz sua pesquisa, a partir de meados dos anos 80, já ligada aos desenvolvimentos temáticos da Nova História num momento em que tais estudos conviviam ainda com abordagens marxistas, do marxismo cultural de influência inglesa e da história social e política.

Para a produção da tese, Mary Del Priore teve a orientação da historiadora Maria Luiza Marcílio, formada em História pela USP, com doutoramento realizado na Universidade de Paris-Sorbonne no ano de 1967, sob orientação de Fernand Braudel e Louis Henry 5 . Importante perceber que as relações de orientação ocorridas na pós-graduação podem ajudar a explicar as filiações teóricas e metodológicas da autora em foco. Tendo formado seu habitus historiográfico no contexto acima descrito, Mary Del Priore recebe a influência direta da historiografia francesa na medida em que sua orientadora conclui parte da sua formação na França, sob orientação direta de Braudel. Com isso, o capital simbólico e acadêmico da orientadora pode ter peso significativo nas escolhas e nas tomadas de posição teóricas e metodológicas e na formação do habitus historiográfico da autora segundo as indicações dadas por Pierre Bourdieu.

Nos anos 90, Mary Del Priore estabelece vínculos ainda mais diretos com a historiografia francesa na medida em que vai à França para a realização de uma especialização em Ciências Sociais, entre 1992 e 1993, e, no ano seguinte, para dar início à

\footnotetext{
${ }^{4}$ Todas as informações sobre a formação, produção e relações acadêmicas da autora discutidas a seguir foram acessadas através do currículo Lattes e podem ser visualizadas no endereço a seguir: http://lattes.cnpq.br/2135122024867878.

${ }^{5}$ Web Site do Departamento de História da Faculdade de Filosofia, Ciências e Letras da Universidade de São Paulo. Disponível em: http://historia.fflch.usp.br/docentes/marialuizamarcilio. Acesso em: 12 de Julho de 2014.
} 
sua pesquisa de Pós-doutorado entre anos de 1994 a 1996. Ambos os cursos foram realizados na Escola de Altos Estudos em Ciências Sociais, grande berço da Escola dos Annales, desde Lucien Febvre.

O interesse da autora por tais temas e métodos da historiografia francesa pode ser verificado em toda a década de 90 na medida em que a mesma ministra cursos e disciplinas na área; além disso, tal interesse é bastante produtivo, uma vez que Mary Del Priore realiza publicações de artigos ligados à história cultural, das mentalidades, da condição feminina e da sexualidade.

\section{Uma fonte para a investigação historiográfica}

É dentro desse contexto que a historiadora Mary Del Priore publica o livro Festas e Utopias no Brasil Colonial no ano de 1994. O texto não fora produzido para fins de titulação ou ligado a alguma pesquisa dentro da universidade, mas para atender às demandas do mercado editorial. O livro compõe a coleção A Caminho das Utopias, concebida e organizada por Hilário Franco Jr. Para a realização da pesquisa, Mary Del Priore contou com auxilio financeiro do $\mathrm{CNPq}$, além de um prêmio concedido pela Organização dos Estados Americanos (OEA) e pelo Ministério dos Negócios Estrangeiros do governo da França.

Publicada pela editora Brasiliense, a coleção A Caminho das Utopias reuniu títulos com temáticas variadas, indo desde o Brasil Colonial até As Utopias Medievais e As Utopias Românticas. Segundo a pesquisa de Carlos Fico e Ronald Polito, era comum na época a publicação de coleções temáticas ligadas à História, com textos acadêmicos voltados também ao grande público.

Com relação às apropriações de teorias, conceitos e métodos da historiografia francesa entre nós, é mister indicar que Hilário Franco Jr, organizador da coleção e apresentador da obra em foco, era naquele momento professor da Universidade de São Paulo, e tivera também a orientação de Maria Luiza Marcilio em seu doutorado, defendido em 1983, na mesma universidade. Além disso, Hilário Franco realizou quatro pós-doutorados na Escola de Altos Estudos em Ciências Sociais, sendo um deles sob orientação direta de Jacques Le Goff.

Percebe-se então um grande entrosamento, uma grande filiação teórica e metodológica em torno da Nova História na medida em que as relações acadêmicas acima descritas dão indicativos de que as apropriações da historiografia francesa passam necessariamente por tais aspectos. É notório que Mary Del Priore produza um texto ligado à Nova História e que sua 
orientadora tenha feito o mesmo, e que o editor da coleção para a qual estava escrevendo tenha tido a mesma orientação e o mesmo percurso acadêmico no campo historiográfico brasileiro e francês.

A escolha desse texto como uma obra de análise nesse artigo justifica-se na medida em que traz inúmeras apropriações de conceitos, teorias e temáticas da historiografia francesa, ao mesmo tempo em que dá pistas do funcionamento de um mercado editorial voltado à história nos anos 90 .

\section{Apropriações epistemológicas na historiografia brasileira}

O livro Festas e Utopias no Brasil Colonial insere-se dentro dos estudos da Nova História na medida em que tem por tema a festa, vista como manifestação cultural das classes populares, ainda que sob tutela e controle direto do Estado Português. Ainda, nota-se nessa obra a presença de alguns aportes teóricos da Nova História Cultural, principalmente naquilo que se relaciona aos conceitos de práticas e representações. Dessa forma, a festa é vista como um rico espaço de trocas e circularidades entre uma cultura de elite e uma cultura popular. Ao mesmo tempo, ela pode ajudar a compreender as relações da festa com a religiosidade popular e católica e com outros aspectos da cultura da sociedade no período colonial. Para a autora, festa é:

Expressão teatral de uma organização social, a festa é também fato político, religioso ou simbólico. Os jogos, as danças e as músicas que a recheiam não só significam descanso, prazeres e alegria durante sua realização; eles têm simultaneamente importante função social: permitem às crianças, aos jovens, aos espectadores e atores da festa introjetar valores e normas da vida coletiva, partilhar sentimentos coletivos e conhecimentos comunitários. Servem ainda de exutórios à violência contida nas paixões, enquanto queimam o excesso de energia das comunidades. A alegria da festa ajuda as populações a suportar o trabalho, o perigo e a exploração, mas reafirma, igualmente, os laços de solidariedade ou permite aos indivíduos marcar suas especificidades e diferenças. (PRIORE, 1994: 10)

Vê-se que a festa está sendo vista nesse estudo dentro de amplo aspecto de abordagens sobre suas funções, características e aspectos sociais. Estando entre o político, o religioso e o simbólico, a festa em si revela não só aspectos da cultura cotidiana erudita ou popular como jogos, danças, além da música, mas também aspectos mais sutis, tais como o prazer, a alegria,

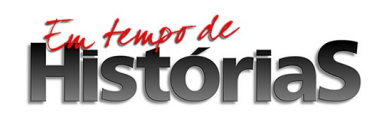


as normas e valores coletivos impostos e partilhados pela sociedade colonial. Um novo tema que requer uma nova abordagem.

Para o estudo das apropriações realizadas pela autora na construção do presente texto, vamos considerar o livro como um todo como uma fonte. Nesse sentido, vamos proceder a uma análise interna, ou seja, tendo como referência o texto em si, na sua introdução, capítulos e conclusão. Ao mesmo tempo, vamos proceder a uma análise externa ao texto, pensando então nos indicativos dados por paratextos, além de considerar as fontes e principalmente as referências bibliográficas.

Começando pela investigação externa, tendo como preocupação principal perceber as referências temáticas, teóricas e metodológicas da autora, vamos considerar o estudo das referências bibliográficas contidas no texto, na seção bibliografia. De início, a fonte revela dois conjuntos de referências. A primeira delas é teórica e metodológica, com textos clássicos da Nova História e da Nova História Cultural e a segunda é temática, em que aparece em grande número obras com a temática das festas, da cultura popular, do carnaval tanto no contexto histórico brasileiro como no contexto histórico francês.

Sendo assim, entre os textos teóricos e metodológicos citados encontram-se Mikhail Bakhtin com A cultura popular na Idade Média e no Renascimento, edição da editora Hucitec publicado em 1987; o livro de Peter Burke: Cultura Popular na Idade Moderna, publicado pela Companhia das Letras, em 1989, e o livro de Roger Chartier: A História Cultural entre práticas e representações, publicado pela Difel, em Lisboa, no ano de 1990 e por fim, destaca-se a obra de Michel Vovelle: Ideologias e Mentalidades, publicado pela editora Brasiliense no ano de 1987.

Oportuno perceber, nesses textos citados, o conhecimento da autora sobre aspectos básicos da Nova História, tais como a questão teórica das mentalidades e do imaginário, sendo este o grande fio condutor do livro em foco, bem como da questão da circularidade entre a cultura de elite e a cultura popular, tema central da obra de Burke e de Bakhtin. Ainda relevante é a presença do livro de Chartier sobre as práticas e representações culturais, denotando conhecimento dos debates da chamada Nova História Cultural, além da presença do texto clássico de Bakhtin, esse dos anos 60, mas de grande influência na terceira e na quarta geração dos Annales. Naturalmente que, na feitura desse texto, a autora fez escolhas teóricas e metodológicas, privilegiando o conceito de mentalidades de Vovelle, o conceito de imaginário, o conceito de representações tal como pensando por Chartier e a ideia de circularidade tal como entendida por Burke, de que se falará adiante.

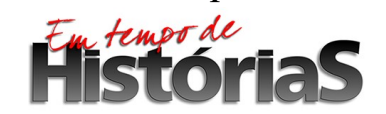


Outro aspecto a ser destacado na análise da bibliografia é a presença de grande número de obras historiográficas cujas temáticas são a festa, o carnaval, a cultura popular e o folclore. Estando a maioria dos títulos em francês, destacam-se na lista livros como Le charivari, de os Jacques Le Goff, Culture Populaire et culture dês elites dans la France Moderne (XV-XVIII) Culture Populaire et culture dês elites dans la France Moderne (XV-XVIII) e La violence au village - Sociabilités et comportements populaires em Artois du XVe au XVIIe siécle de Robert Muchembled; Les métamorfhoses de la fête em Provence - 1750-1820 de Michel Vovelle; e, finalmente, Le Peuple de Paris. Essai sur la culture populaire au XVIIIe, de Daniel Roche. Ainda, La fête revolutionnaire -1789-1799, de Mona Ozouf, além do livro de Nicole Pellegrin: La bachelleries-organizations et fêtes XVe-XVIIIe. A maior parte dos textos elencados foram publicados durante a década de 80 , momento ainda de domínio da terceira geração dos Annales no campo historiográfico francês.

A bibliografia citada pela autora revela o intenso diálogo teórico e metodológico entre a historiografia brasileira e a francesa, mas também é revelador de um contato direto com a bibliografia francesa voltada à temática da cultura popular e da festa como manifestação cultural.

Com isso, podemos apontar três formas principais de apropriação que ocorrem no livro. Em primeiro plano, a apropriação no nível teórico e metodológico que será discutida adiante, em segundo, a apropriação que se dá no nível temático, na medida em que o tema da festa é amplamente abordado na historiografia francesa da terceira geração dos Annales como indicado acima. Há ainda uma terceira forma de apropriação que a análise da obra revela. São citações de autores que não vêm acompanhadas de indicação bibliográfica e que aparecem ao longo do texto quando a autora procura sustentar alguma ideia, ou mesmo pelo uso de termos, tais como "economia psíquica" "processo civilizatório" ou "longa duração". É possível ainda, captar certas ressonâncias teóricas oriundas principalmente da antropologia, sobretudo quando a autora dá definições para o conceito de cultura ou pensa nos significados da festa. Ainda nesse sentido, é notória a utilização de antropólogos como Levi-Strauss, Cliford Geertz, além da indicação direta dos trabalhos da antropologia histórica de Jean-Louis Flandrin e Maurice Aymard, que, como os outros, não são referenciados na seção bibliografia.

Para Mary Del Priore, o estudo das festas como objeto historiográfico pode levar "os historiadores a refletir sobre as abordagens metodológicas que lhes permite investigar 'a cultura do povo"”. (PRIORE, 1994: 10). Assim, a festa é um caminho que poderá revelar ao historiador a cultura do povo, e nesse sentido, a metodologia de pesquisa a ser empregada é

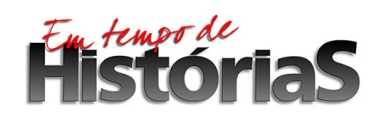


fundamental. Para a autora, a festa como objeto tem sido mais descrita do que explicada, diz Mary Del Priore: "Levi-Strauss diz que ela deve responder a uma necessidade e preencher uma função" (PRIORE, 1994: 10). Embora não citando a obra da qual extrai tal ideia, a autora dela se serve para buscar então a investigação das funções da festa e indica o caminho metodológico para que isso possa ocorrer:

(...) os documentos históricos não elucidam necessariamente as funções formais embutidas na festa. Para captá-las, é necessário religar todas as suas intervenções por meio de um sistema global de interpretações que não deve negligenciar nenhuma manifestação de sua prismática vivência. Por isso, nesse estudo, não serão ignorados os gestos, os bailados, o entretenimento, a violência, as funções mágicas e políticas da festa. (PRIORE, 1994: 11).

Assim, a análise das fontes deve ser feita para a autora dentro de outro enfoque metodológico, a nosso ver, bastante próximo da metodologia da "descrição densa" de Clifford Geertz. Quando a autora fala em "religar todas as suas intervenções" ou que "não deve negligenciar nenhuma manifestação de sua prismática vivência" a autora está claramente se apoiando na metodologia da antropologia de Geertz. Contudo, em nenhum momento, a autora faz referências a esse autor diretamente, o que nos levar a apontar a hipótese de uma antropologização ${ }^{6}$ indireta da historiografia brasileira que se dá via bibliografia francesa.

Tal afirmação se confirma na medida em que autora assim se coloca diante dessa questão: “A história da festa, está aqui tratada à luz da abordagem das mentalidades e da cultura. Nossa preocupação será em inquirir que significado a festa possuía para os vários segmentos da sociedade" (PRIORE, 1994: 10). Quando a autora fala em abordagem das mentalidades e da cultura e usa a palavra significado, ela se coloca indiretamente próxima à antropologia de Geertz. Para esse antropólogo, a cultura é vista como uma rede de significados e nesse sentido, o pesquisador é aquele que interpreta tais significados. (GEERTZ, 1978: 16-17)

Para a questão da circularidade cultural, ou seja, para os estudos das relações e interações culturais entre a elite e o povo, a autora constrói sua metodologia tendo por base os estudos de Peter Burke sobre a cultura popular europeia, e através deste, toma partido numa ampla discussão metodológica em torna da circularidade cujos nomes principais são Bakhtin e

\footnotetext{
${ }^{6}$ Para Astor Antônio Diehl, ao receber influência direta e ao estabelecer uma intensa relação de apropriação de teorias, conceitos e métodos da terceira geração dos Annales, a historiografia brasileira sofreu um processo que ele chama de antropologização indireta que se deu via relação com a produção do grupo dos Annales, na medida em que esta se caracteriza pela intensa relação epistemológica com a antroplogia. DIEHL, 1993.
} 
Carlo Ginzburg. Tal autor não é citado por Mary Del Priore, mas aparece amplamente na obra de Peter Burke, ${ }^{7}$ o que nos leva a inferir que a tomada de posição metodológica da autora se deu através da leitura de Burke em que ela discute e problematiza acerca da questão.

Para a autora: "O grande estudioso da cultura popular na Europa Moderna, Peter Burke, sugere ainda que, até o século XVI, elite e povo participavam de uma mesma cultura e explicitavam tal convívio por meio das festas”. (PRIORE, 1994: 12). Há de se notar a presença na bibliografia utilizada pela autora do texto de Mikhail Bakhtin, obra de referência nesse tipo de estudo das circularidades culturais, muito embora com um enfoque teóricometodológico mais próximo das contribuições da Linguística. Embora citado em um ou outro momento ao longo do texto, não foi esse o tratamento teórico escolhido pela autora para tratar do seu objeto.

Com isso, seguindo a postura teórico-metodológica de Peter Burke, a autora encara a festa como uma ocasião em que ocorre uma grande circularidade cultural entre a elite e o povo, tendo o Estado Moderno Português a função de introjetar valores e normas de conduta ao povo. Dessa forma, a autora está enxergando uma circularidade que se dá principalmente de cima a baixo, ou seja, percebendo o Estado Português na Colônia como aquele que irá fazer com que as pessoas possam introjetar suas pulsões e individualizar normas de comportamento. Dessa maneira, a autora considera que o Estado pode ter ensejado "uma convergência na maneira como a elite e o povo usavam os mesmos produtos culturais, entre eles a festa" e continua:

Investindo na hipótese de Burke e comprovando que a festa sustentava a farsa, a fantasia e o divertimento de muitos, será importante rastrear os níveis de circularidade que levavam informações da elite para o povo, ou por entre culturas diferentes (no caso brasileiro, a negra e indígena), que serviram-se da festa, da procissão da "Entrada" como espaço comum de trocas. (PRIORE, 1994: 45)

Percebe-se pela citação acima, a ampliação do conceito de circularidade cultural tal como aparece na historiografia europeia, desde Bakhtin, Peter Burke e Carlo Giznburg. O uso que Mary Del Priore faz do conceito nos leva a aventar uma adaptação teórica ao objeto

\footnotetext{
${ }^{7}$ Peter Burke, embora não estando diretamente ligado ao grupo dos Annales, é um estudioso dos trabalhos do grupo e no seu livro sobre a cultura popular europeia a ampla discussão em torno da circularidade cultural é abordada inúmeras vezes ao longo do seu livro, sobretudo no que concerne aos seus aspectos teóricos e metodológicos que permitiram a abordagem das suas fontes e a construção de suas hipóteses. BURKE, Peter. Cultura Popular na Idade Moderna. São Paulo: Companhia das Letras, 1995.
}

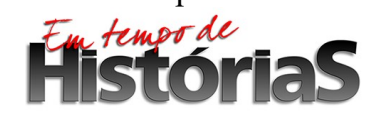


empírico tratado pela autora. Com isso, a ideia de circularidade é ampliada para se pensar outras de formas de circulação cultural; em primeiro lugar, a festa é analisada como uma manifestação cultural com ampla participação popular, mas com o controle direto do Estado Português na Colônia que busca impor valores culturais ao povo, ao mesmo tempo, a festa seria um espaço convergente onde as diferentes culturas que formam as etnias coloniais viveriam e experimentariam amplas possibilidades de trocas culturais. Assim, a circularidade aqui proposta vai muito além da ideia de circularidade entre elite e povo.

Com efeito, existem outras formas em que a circularidade cultural pode ocorrer, quando se consideram as festas propriamente ditas. De origem europeia e portuguesa, a maior parte ligadas a cultos sagrados e profanos quase sempre de caráter oficial, ou seja, ligados ao Clero ou a Monarquia, tais festas chegam à colônia dentro do processo colonial e sofrem transformações originais, em que outras formas de circularidades culturais estão em jogo. Com isso, vê-se que a complexidade do passado histórico colonial de certa maneira levou a autora a ampliar a noção de circularidade como demonstrado até aqui.

Outra questão relevante a ser discutida diz respeito à apropriação feita pela autora dos conceitos de práticas e representações também como pensada por Roger Chartier. Articula-se dentro dessa questão teórica, outra de caráter metodológico concernente ao tratamento e a forma de trabalhar as fontes escolhidas pela autora na realização da pesquisa.

Para a pesquisa que originou o livro, Mary Del Priore utilizou, na maior parte do tempo, fontes eclesiásticas e oficiais, ou seja, relacionadas ou à Igreja e suas companhias, ou ao Estado Português. Além dessas fontes, aparecem relatos de viajantes, poetas e um ou outro memorialista e alguns folcloristas. Tais fontes colocam, para a autora, o problema assim descrito: "Mesmo que esses narradores provenham das elites, e sejam portadores de um instrumento de poder bastante exclusivo - a escrita - aquilo que eles viram nos ajudará, mais para a frente, a perceber o que não quiseram registrar". (PRIORE, 1994: 17)

E continua a analisar suas fontes:

Olhar domesticado, o deles será também um olhar que representa uma festa desejada, ou idealizada, por um dos segmentos da sociedade. Para os que estivessem articulados com o Estado Moderno ou com a Igreja, a festa devia simbolizar o poder do monarca ou do panteão católico; o que não obrigava necessariamente o vivido histórico a corresponder à representação que se fazia dela. No entanto, essas complexas mediações entre a vida real e a imagem que alguns privilegiados espectadores faziam da festa ajudam a perceber uma das funções que esta teria no período em questão. A economia de palavras sobre a participação popular e os encômios que cercam o

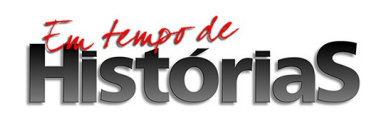


desempenho das elites determinam um discurso dos dominantes --- quase uma confissão --- sobre os seus medos e a consequente necessidade de provocar a exclusão das classes subalternas do evento festivo. (PRIORE, 1994: 18)

Ao colocar o problema nesses termos, ou seja, o fato de que suas fontes são oriundas das elites coloniais e que suas visões e imagens construídas sobre a festa estão carregadas de idealizações e representações que nem sempre guardam relações com a realidade histórica, Mary Del Priore está claramente se apropriando dos conceitos de práticas e representações de Chartier.

Para esse autor, as representações históricas estão intimamente ligadas às práticas sociais que as originaram. Ao mesmo tempo em que próximas, as representações podem se colocar de maneira bastante distante das práticas ou da realidade histórica estudada. Com isso, representações construídas por uma classe ou grupo social podem guardar íntimas relações com a realidade histórica, ao mesmo tempo em que podem se distanciar dessa realidade, construindo uma visão do passado que não corresponde necessariamente à realidade histórica vivida pelos testemunhos. (CHARTIER, 1996: 13-28)

Nesse sentido, ao inquirir suas fontes e as representações da festa que aí podem ser visualizadas, a autora está consciente de que tais representações podem idealizar a festa, ou seja, podem esconder outras realidades históricas, outras práticas que não aquelas descritas nas referidas testemunhas do passado. Portanto, tal questão teórica possui uma articulação metodológica fundamental na medida em que vai guiar o olhar do historiador sobre suas fontes e vai dar o tom na prática de pesquisa e na construção do texto histórico. É esse esforço heurístico que permite à autora vislumbrar, nessas fontes oficiais e carregadas de representações idealizadas sobre a festa, a participação popular, as mentalidades das elites, a circularidade cultural entre seus diferentes participantes.

Questionando as fontes que dão conta de um festejo ou "Entrada" que teve lugar na cidade de São Paulo em 1770, Mary Del Priore vai extraindo dessas fontes questões que não estão aparentes no texto. Questionando as representações do festejo presentes na fonte, a autora encontra outras práticas, tais como a participação popular ou mesmo transgressões sociais embutidas e presentes na festa e não claramente descritas no texto. Vejamos as palavras da autora a respeito:

Os narradores dessas festas têm, todavia, a tendência de enxergar nos dois pólos sociais procedimentos uniformes que tendem a esvaziar o vivido 
histórico. Eles tendem a mimetizar as apropriações e circularidades que medravam no interior da comemoração, dando a impressão de que segmentos sociais socialmente polarizados atuavam de forma homogênea durante a festa. (PRIORE, 1994: 40)

Desta maneira, Mary Del Priore coloca o problema de como proceder a análise desse tipo de fonte, e fazendo isso, constrói sua leitura das mesmas em sentido oposto, pois na representação analisada no parágrafo a seguir ao citado acima, a autora faz os questionamentos se tal representação efetivamente corroborava as práticas sociais referentes ao festejo.

Novamente as palavras da autora ao final do segundo capítulo:

A festa começava pelo desfile de símbolos (as "máscaras", os arautos, as bandeiras, o mastro, a decoração das ruas e os foguetes), que eram apropriados diferentemente pelas diversas camadas da população. Ora status, ora poder, ora resistência, a cultura popular ou de elite davam funções diversas a esses vários símbolos. Jogos de espelhos onde os membros da sociedade colonial refletiam-se distintamente, as festas iniciavam-se com um feixe de símbolos que anunciavam um tempo de identidades encobertas, ou falsificadas, numa constelação de utopias. (PRIORE, 1994: 41)

Vê-se, então, que o procedimento teórico-metodológico apropriado pela autora a partir da historiografia francesa - através do uso dos conceitos de práticas e representações trabalhados por Roger Chartier — permitiu-lhe vislumbrar, através da pesquisa de fontes oficiais, outras formas de vivência histórica tais como, a cultura popular e de elite, suas circularidades e tensões sociais, as identidades encobertas ou falsificadas, tudo isso no plano da cultura simbólica propiciada pelo estudo das festas e festividades coloniais.

Outro caminho de apropriações trilhado por Mary Del Priore no texto ora em análise refere-se à temática da história das mentalidades e da história do imaginário. Sendo campos de estudos historiográficos também abertos pela terceira geração dos Annales, tais enfoques possuem significativa penetração na historiografia brasileira dos anos 80 e 90 . Ainda que se trate de campos distintos, existe certa proximidade teórica e metodológica que permite a alguns autores realizarem pesquisas que contemplem ambas as perspectivas de análise histórica (BARROS, 2000).

Contudo, as diferenças são importantes e pontuá-las é necessário ainda que sucintamente. Enquanto a história das mentalidades opera em uma perspectiva mais ligada à longa duração e refere-se a objetos de análise mais sutis, tais como os sentimentos humanos 
diante da morte ou a medos em geral, e claramente ampara-se na ideia de um inconsciente coletivo ou das representações coletivas; a história do imaginário por sua vez está mais ligada a uma perspectiva de média ou curta duração, e procura, nesse caminho, buscar entender e relacionar as imagens visuais, verbais e mentais sobre determinado tema, e principalmente, busca relacionar tais imagens com outras questões pertinentes à sociedade analisada, tais como as estrutura de classes ou mesmo aspectos do político ou do econômico.

As observações acima são pertinentes em nossa investigação, na medida em que Mary Del Priore apresenta seu texto como ligado à perspectiva da história das mentalidades como demonstrado em citação anterior, e faz uso de termos tais como "utensilagem" mental, universo mental, e principalmente o termo mentalidade. Contudo, sua pesquisa não pode ser considerada como sendo exclusivamente um estudo de história das mentalidades uma vez que seu objeto de análise são as festas nas suas amplas manifestações e não sentimentos ou ideias inscritas na coletividade e perseguidas na longa duração.

Assim, a hipótese aventada para a compreensão desta questão é a de que a autora se serviu desses termos em alguns momentos em suas análises para responder às demandas colocadas pelas fontes e principalmente quando seu enfoque estava direcionado à história do imaginário. Com isso, o que se percebe é que a autora mesclou termos comuns à história das mentalidades quando se debruçava nas fontes em busca de imagens em torno da festa. Desta forma, seu estudo possui nuances significativas da história do imaginário com uso de termos e conceitos da história das mentalidades. No entanto, tal procedimento é bastante comum nesse tipo de estudo histórico, uma vez que o imaginário compõe a mentalidade de um grupo ou sociedade. Dessa forma, a autora persegue o imaginário colonial pois este contribui na formação de uma mentalidade. Com isso, podemos afirmar que seu estudo pode ser descrito como um estudo de história das mentalidades e do imaginário.

No estudo do imaginário colonial em torno dos gigantes, a autora consegue vislumbrar um "universo mental popular" onde tais imagens se associavam à abundância material e corporal. (PRIORE, 1994: 53) Quando realiza a análise dos significados do milagre no imaginário colonial dentro da festividade, novamente a autora se serve de tais termos, vejamos: "Tal como a festa emoldurava, o milagre tinha a característica de ser ao mesmo tempo um fenômeno sagrado e profano. Essa simbiose é que vai dar função prática na mentalidade das pessoas que festejam (...)" (PRIORE, 1994: 54).

Quando analisa o imaginário colonial, descrito nas fontes em torno das imagens da infância, novamente a autora segue o procedimento metodológico apontado, segundo a autora:

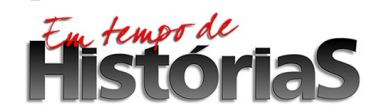


"Na Colônia elas aparecem em cenas cujas descrições permitem ler uma nova sensibilidade incorporada pelas mentalidades em relação à infância que, nessa fase, ganha prestígio e simbolismo específicos." (PRIORE, 1994: 74).

Após a apresentação de uma longa fonte descritiva sobre a presença de crianças nas festividades coloniais, assim a autora se expressa: "Expressões como "terníssimas", "cândidas" e "inocentes" ressaltam a mentalidade indicativa da crença de que as crianças nas suas pueris qualidades eram ouvidas por Deus; sua inocência encobria o pecado dos adultos". (PRIORE, 1994: 75) Assim, as imagens das crianças como "cândidas" ou "inocentes" indicam uma mentalidade específica em torno da criança.

Nesse processo de apropriação de conceitos, teorias e métodos da Nova História e da Nova História Cultural é importante notar mais uma vez um processo de adaptação dessas teorias à realidade histórica do Brasil Colonial. Com efeito, nas suas análises em torno do imaginário é interessante perceber que Mary Del Priore incorpora a noção de circularidade cultural mais ampla conforme discutido acima. Com isso, no imaginário colonial é possível vislumbrar uma gama de circularidades que são não só as de alto a baixo, mas também incluem a circularidade entre a cultura europeia, a indígena e negra, entre Europa e América, em vários e complexos sentidos. Vejamos:

\begin{abstract}
A intimidade, portanto, com as coisas da Colônia permite que imagens sejam exportadas e reelaboradas na metrópole ajudando a dimensionar os quadros mentais da época sobre a Terra de Santa Cruz e a América. Percebe-se nitidamente a circulação de ideias nos dois sentidos e enquanto as representações sobre a cultura nas colônias portuguesas invade as festas no Brasil, ou em Portugal, uma canal de informações estabelece-se entre aqui e o além-mar. (PRIORE, 1994: 57)
\end{abstract}

Trecho significativo, a citação acima revela não só a hipótese apontada, como também permite a visualização de uma intensa bricolagem teórica e metodológica que está presente em todo o texto na medida em que vemos os termos "imagem", "circulação", "representação" e "quadros mentais" sendo utilizados para a investigação de uma única questão.

\title{
Conclusão
}

A historiografia e seu amplo conjunto de características, tais como temas, teorias, métodos e práticas de pesquisa estão sujeitos à mudança como qualquer outra manifestação

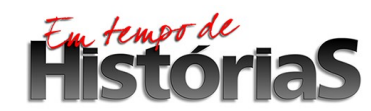


cultural humana. Nesse sentido, a historiografia brasileira possui uma rica história marcada principalmente pela sua aproximação epistemológica com outros campos de produção fora do país e que, de certa maneira, influem para que tais mudanças possam acontecer.

Dessa forma, os anos 80 e 90 podem ser considerados como um rico momento em que tais mudanças podem ser visualizadas e investigadas. Como visto a aproximação teórica e metodológica dos historiadores brasileiros com relação à terceira e à quarta geração dos Annales foi à grande responsável pela mudança na Matriz Historiográfica Brasileira, somadas a outras questões referentes ao contexto sócio-histórico em que tal processo ocorrera.

Com isso, inquirir a produção historiográfica do período, tendo em foco o processo de apropriações de temas, teorias e métodos é um profícuo caminho que pode revelar os rumos trilhados pelos historiadores brasileiros em direção a novos temas, novos objetos e novas abordagens. Com efeito, o texto elencado para esse estudo é revelador não só das mudanças nos temas de pesquisa, mas principalmente revela o uso de conceitos, teorias e métodos da produção historiográfica francesa como um rico processo de adaptação à realidade histórica brasileira.

\section{Referências Bibliográficas}

BARROS, José D'Assunção. Imaginário, Mentalidades e Psico-História: Uma discussão historiográfica. Revista Eletrônica do Centro de Estudos do Imaginário. Universidade Federal de Rondônia, Porto Velho, RO. 2000. Disponível em: http://www.cei.unir.br/artigo71.html\#_ftn1. Acesso em 07 de Julho de 2014.

BELIEIRO, Thiago Granja. História (sociológica) da História: Proposições para o uso de conceitos de Pierre Bourdieu nas análises historiográficas. Não publicado.

BOURDIEU, Pierre. Os Usos Sociais da Ciência: Por uma sociologia clínica do campo científico. São Paulo, Edunesp, 2002.

BOURDIEU, Pierre. O Poder Simbólico. São Paulo: Bertrand Brasil, 1977.

BURKE, Peter. A Escola dos Annales. São Paulo, Unesp, 1990.

BURKE, Peter. O que é História Cultural? Rio de Janeiro, Zahar, 2005.

BURKE, Peter. Cultura Popular na Idade Moderna. São Paulo: Companhia das Letras, 1995.

CAPElATO, Maria Helena Rolim. Perfil dos Programas de Pós-Graduação em História do País. REVISTA BRASILEIRA DE HISTÓRIA. São Paulo, Vol 14, n 28, 271-303, 1994.

CERTEAU, Michel. A Operação Historiográfica. In: CERTEAU, Michel. A Escrita da História. Rio de Janeiro: Forense Universitária, 2002. : 45-115.

CHARTIER, Roger. A história cultural: entre práticas e representações. 2. ed., Portugal: Difel, 2002.

DIEHL, Astor Antônio. A cultura historiográfica brasileira nos anos 1980. Porto Alegre, Evangraf, 1993.

FERREIRA, André Lopes et AL (orgs) História: Diálogos e Paradigmas. Jundiaí, Paco Editorial, 2013.

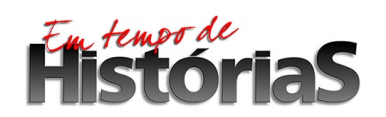

(PPGHIS/UnB) No. 30, Brasília, Jan - Jul 2017 ISSN 2316-1191 
FICO, Carlos e POLITO, Ronald A história no Brasil (1980-1989) elementos para uma avaliação historiográfica. Ouro Preto, Editora UFOP, 1992.

FERREIRA, Antonio Celso. A Historiografia profissional Paulista: Expansão e descentramento. In: GLEZER, Raquel (org.) Do passado ao futuro: Edição comemorativa dos 50 anos da Anpuh. São Paulo, Editora Contexto, 2011.

GLEZER, Raquel (org.) Do passado ao futuro: Edição comemorativa dos 50 anos da Anpuh. São Paulo, Editora Contexto, 2011.

GEERTZ, Clifford. A Interpretação das Culturas. Rio de Janeiro: Zahar Editores, 1978.

HUNT, Lynn. A Nova História Cultural. São Paulo: Martins Fontes, 1992.

PRIORE, Mary Del. Festas e Utopias no Brasil Colonial. São Paulo, Editora Brasiliense, 1994.

RAMOS, Igor Guedes. Genealogia de uma operação historiográfica: as apropriações dos pensamentos de Edward Palmer Thompson e Michel Foucault pelos historiadores brasileiros na década de 1980. 2014. 378: Tese (Doutorado em História e Sociedade) Unesp, Assis, 2014.

REIS, José Carlos. Escola dos Annales: A inovação em História. São Paulo, Paz e Terra, 2004.

ROJAS, Carlos António Aguirre. Tese sobre o itinerário da historiografia do século 20: uma visão de longa duração. In: ROJAS, Carlos Aguirre e MALERBA, Jurandir. Historiografia Contemporânea em Perspectiva Crítica. Bauru, Edusc, 2007. p. 13-31.

ROIZ, Diogo da Silva, SANTOS, Jonas Rafael dos. As Transferências Culturais na Historiografia Brasileira: Leituras e apropriações do movimento dos Annales no Brasil. Jundiaí, Paco Editorial, 2012. 